\title{
Stereotactic Radiosurgery for Treatment of Operculoinsular Refractory Epilepsy After Incomplete Resection in a Child
}

\author{
Canh Duy Phan' \\ Anh Tuan Dang ${ }^{2}$ \\ Van Anh Ton-Nu (iD) ${ }^{3}$ \\ Huu Son Nguyen $\mathbb{D}^{4}$ \\ Nhu Hiep Pham' \\ 'Oncology Center, Hue Central Hospital, \\ Hue City, Vietnam; ${ }^{2}$ Neurology \\ Department, National Hospital of \\ Pediatrics, Ha Noi, Vietnam; ${ }^{3}$ Pediatric \\ Department, Hue University of Medicine \\ and Pharmacy - Hue University, Hue City, \\ Vietnam; ${ }^{4}$ Pediatric Center, Hue Central \\ Hospital, Hue City, Vietnam
}

\begin{abstract}
A 13-year-old right-handed girl had operculoinsular refractory epilepsy with several seizures per week after temporal lobe epilepsy surgery despite appropriate anticonvulsant therapy. Instead of reoperation, she underwent stereotactic radiosurgery (SRS), which was performed using a linac-based Elekta Axesse SRS machine with a marginal dose of 24 Gy (gross target volume: $6.67 \mathrm{~cm}^{3}$ ) in one fraction. Post-radiosurgery, she had no clinical or radiological complications. She was maintained on two anti-seizure medications following treatment (valproate and levetiracetam) and was seizure free at the time of this report (during four weeks after SRS). Monthly follow-up was planned for the evaluation of long-term outcomes. SRS may be a safe option for treating intractable focal epilepsy or recurrent epilepsy after surgery failure in children.
\end{abstract}

Keywords: stereotactic radiosurgery, epilepsy, refractory, epilepsy surgery

\section{Introduction}

Although anti-epileptic drugs are the mainstay of epilepsy treatment, up to $40 \%$ of children with epilepsy do not achieve seizure freedom with medical therapy, ${ }^{1}$ and approximately $30 \%$ of patients with focal epilepsy develop refractory epilepsy. ${ }^{2}$ After undergoing excisional surgery for refractory epilepsy, children have improved quality of life with a complication rate of less than $5 \%{ }^{3}$

In addition to standard epilepsy surgery, stereotactic radiosurgery (SRS) can eliminate focal epileptogenic lesions in both adults and children. Recent studies on the use of radiosurgery in the treatment of focal epilepsy suggest that medically intractable seizures remit at clinically significant rates following SRS. $^{4-6}$

However, $27 \%$ of children fail to achieve seizure freedom within six months of surgical treatment of intractable epilepsy. ${ }^{7}$ Since the first report on reoperation for recurrent temporal lobe epilepsy in 1954 by Penfield, several reoperation techniques for intractable temporal lobe epilepsies have been reported. However, indications, outcomes, and risks of SRS have not been well documented. $^{8}$

We report a case of operculoinsular refractory in a child after epilepsy surgery due to insufficient resection of the region with focal cortical dysplasia. The patient underwent SRS instead of reoperation to eliminate epileptic foci.
Correspondence: Van Anh Ton-Nu

Pediatric Department, Hue University of Medicine and Pharmacy - Hue University, 06 Ngo Quyen St, Hue City, Vietnam Tel +84982066063

Email tonnuvananh@huemed-univ.edu.vn 


\section{Case Report}

The patient, a 13-year-old girl, had no significant medical history till the age of six. She started experiencing complex focal seizures of unknown cause at the age of six. Seizure episodes occurred when she turned her head to the left. During the episode, she experienced drooling due to loss of awareness. Seizures lasted under two minutes and occurred 5-10 times per week. Various anti-epileptic drugs, including oxcarbazepine, topiramate, levetiracetam, valproate, and clonazepam, were prescribed, but failed to control the seizures. Abnormal paroxysmal spike and waves on electroencephalography (EEG) indicated a right temporal lobe focus, which was corroborated by decreased uptake in the right temporal lobe on fluorodeoxyglucose-positron emission tomography (SUVmax: 5.4-6.9 in the right temporal lobe vs $8.5-8.6$ in the left temporal lobe) and by magnetic resonance imaging (MRI) findings of insular focal cortical dysplasia (Figure 1).

In September 2019, the patient underwent excisional surgery at a paediatric hospital in Vietnam. Right frontotemporal craniotomy was performed, and the Sylvian fissure was widely opened. Intraoperative electrocorticography (ECoG) localised all epileptiform activities to the insula, frontal and parietal opercula. These findings corroborated with those of previously performed surface EEGs. Thereafter, the right insula and frontal and parietal opercula, which were the epileptogenic regions, were removed, and the temporal operculum was preserved. Repeat ECoG did not show residual epileptiform activity beyond the excision line.

On post-operative MRI, the removal regions without damage to the adjacent cortices and hippocampus was confirmed. Focal cortical dysplasia was diagnosed based on pathological examination results. The patient continued to receive levetiracetam, oxcarbazepine and phenytoin. Postoperatively, the patient was seizure free and had left hemiparesis and language impairment. Three days post-operatively, seizures recurred with increasing frequency (Engel's class IIIB) but with somewhat decreased intensity.

Subsequently, she experienced complex focal seizures, sometimes with secondary generalisation, 10-15 times per month (Engel's class IIIB). Various anti-epileptic drugs and combinations, including oxcarbazepine, phenytoin, levetiracetam, clonazepam, and valproate, were administered before she was diagnosed with medically intractable epilepsy. Repeat MRI showed residual lesions in the operculo-insular area (Figure 2), which were consistent with the abnormal discharges on EEG. Further surgery was not considered because of the high risk of damage to the adjacent cortices and hippocampus, and the patient was referred to our hospital for SRS for medically intractable seizures following temporal lobe epilepsy surgery failure.

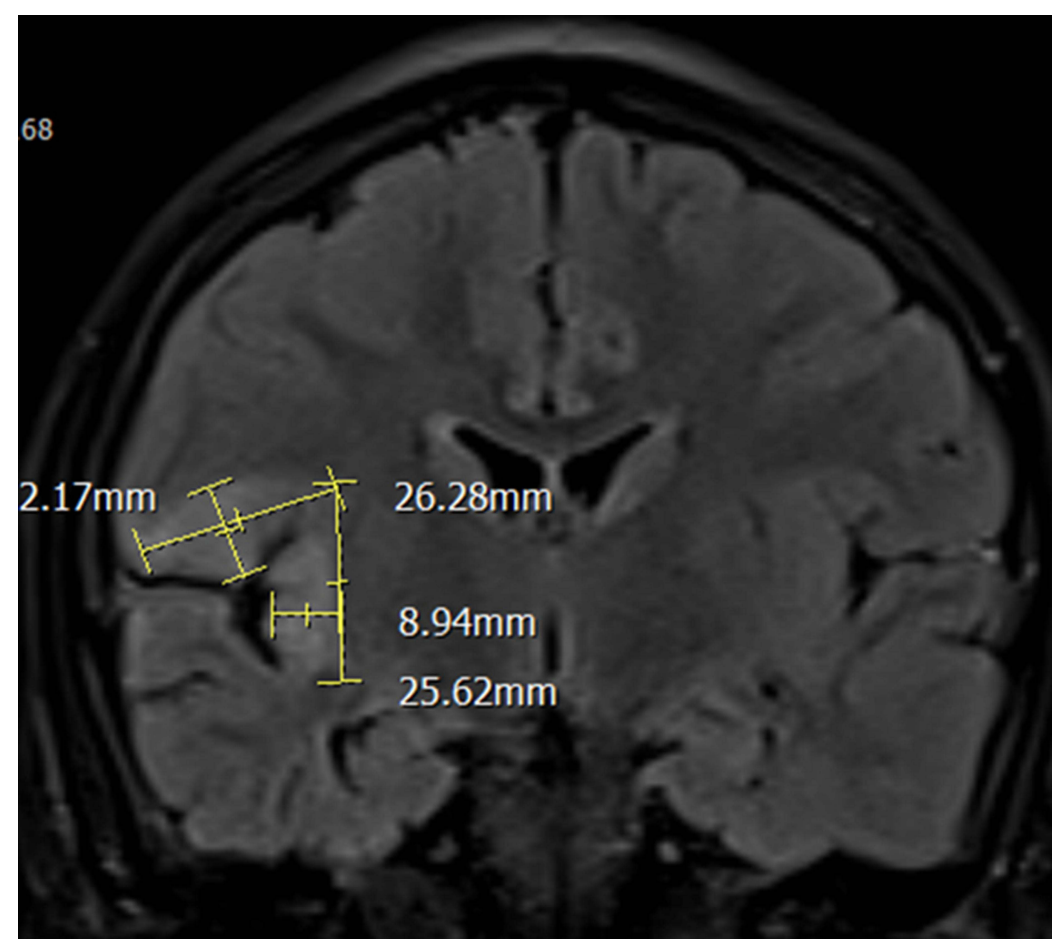

Figure I Preoperative magnetic resonance image showing focal cortical dysplasia at the insula, frontal and parietal opercula. 


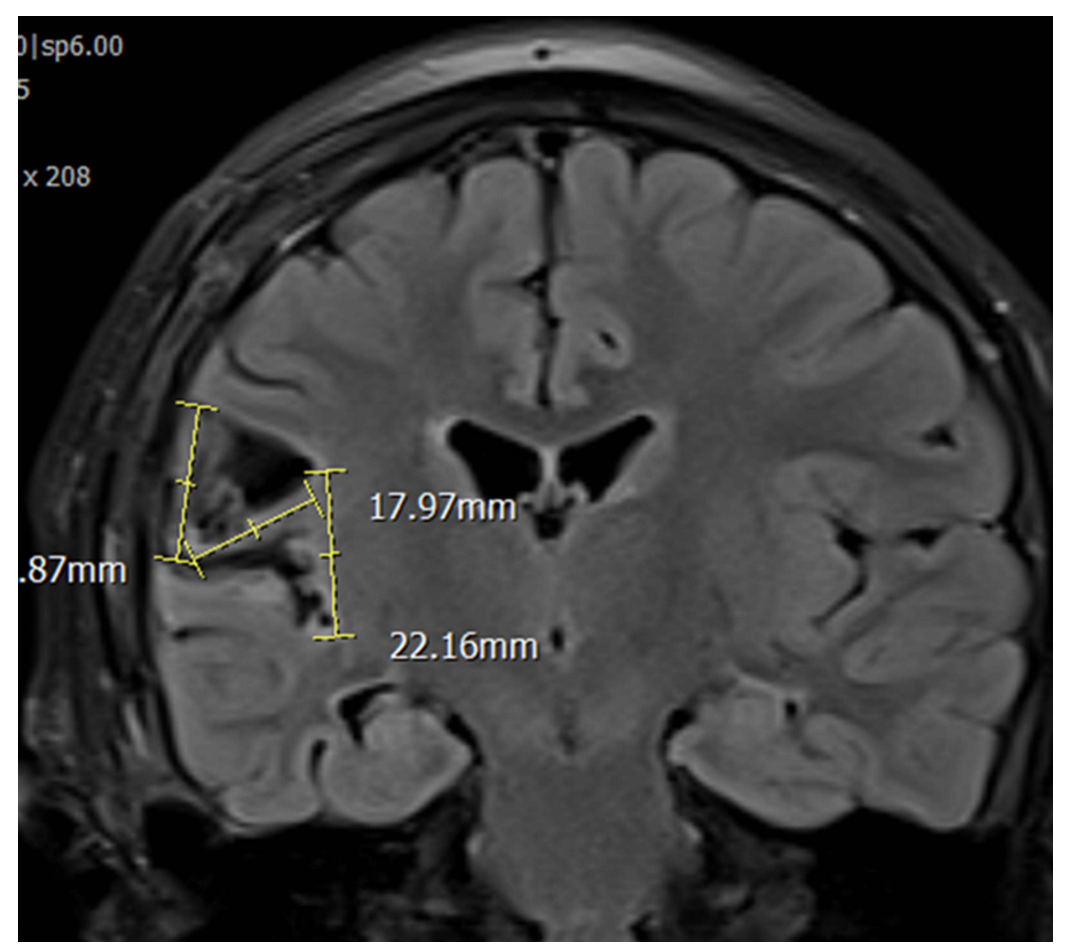

Figure 2 Post-operative fluid-attenuated inversion recovery magnetic resonance image showing increased signal intensity in the right insula, which was the epileptogenic region.

Surface EEG (Figure 3) and MRI (Figure 4) performed at our hospital during re-evaluation of the patient showed the same findings as those reported previously. A multidisciplinary team consisting of a neurologist, neurosurgeon, radiologist, and others recommended SRS instead of reoperation. Informed consent was obtained, and SRS was performed using a linac-based SRS machine with a marginal dose of one fraction of $24 \mathrm{~Gy}$ (gross target volume: $6.67 \mathrm{~cm}^{3}$ ) (Figures 5 and 6).

Following SRS, the patient did not have any acute complications. Nonetheless, dexamethasone was administered for a short period to prevent post-operative cerebral oedema. The patient was maintained on two anti-epileptic medications (valproate and levetiracetam) following SRS.

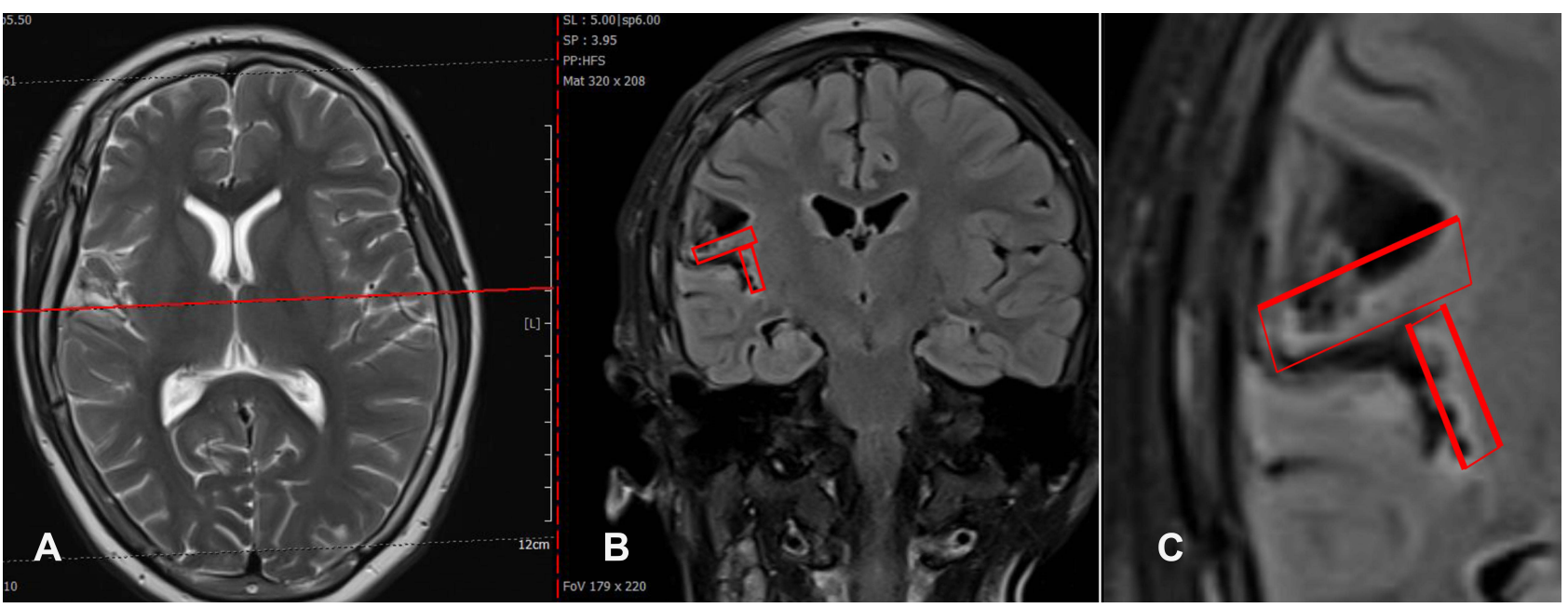

Figure 3 Pre-radiosurgery coronal $(\mathbf{A})$, axial $(\mathbf{B})$ and zoom out $(\mathbf{C})$ view magnetic resonance images showing residual lesions in the operculo-insular area (within the red rectangles). 


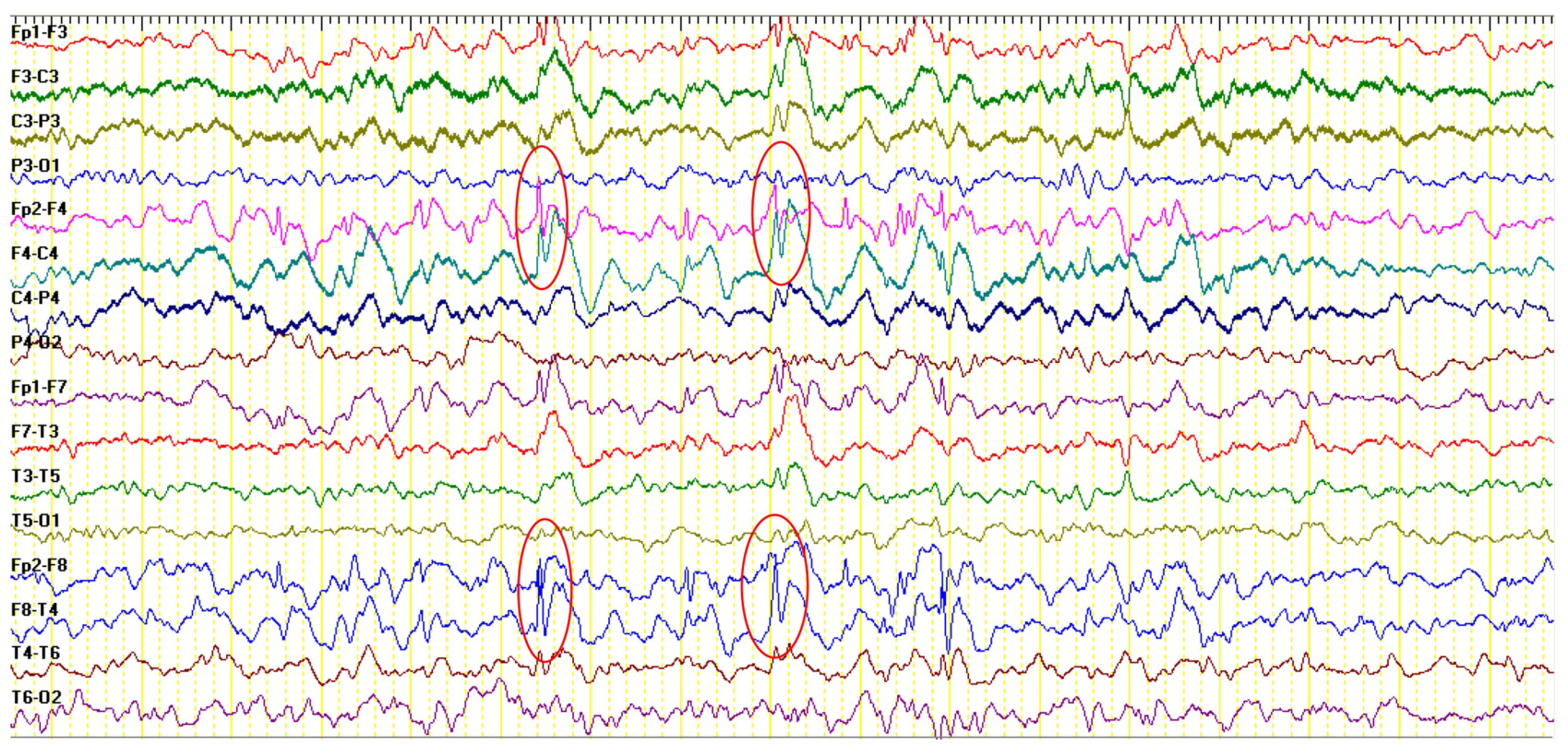

Figure 4 Pre-radiosurgery interictal electroencephalogram showing sharp waves (within the red circles) in the right temporal-frontal area, which is suggestive of right temporal-frontal epilepsy.

She was seizure free at the time of this report (during four weeks after SRS). Monthly follow up was planned for seizure evaluation and to perform EEG and MRI. She will be gradually reduced the daily dose and/or the number of anti-epileptic medications.

\section{Discussion}

To our knowledge, this is the first reported case of the use of SRS, instead of reoperation, to treat operculoinsular refractory epilepsy after incomplete resection in a child. Non-invasiveness, safety, low cost, and low post-operative morbidity are the main advantages of radiosurgery over open surgery. ${ }^{9}$ In contrast, slow response and delayed radiation necrosis are disadvantages of SRS. ${ }^{10}$ Therefore, the use of SRS for intractable epilepsy treatment has been subject to controversy. In 1994, Barcia et al published the first report on the effect of radiosurgery on seizure control. ${ }^{11}$ They studied 11 patients with epileptic foci who were treated with doses ranging from 10 to $20 \mathrm{~Gy} .{ }^{12}$ In the late 1990s, two papers reported seizure reduction after gamma knife radiosurgery for brain tumours. ${ }^{13,14}$ These studies included 23 patients with temporal lobe lesions and 24 patients with extratemporal lesions and yielded encouraging results in terms of improved seizure control and freedom from seizures. Despite the limitations of these studies, positive results in terms of good seizure control and very low complication rates aroused interest in the possible role of radiosurgery in the treatment of lesional epilepsy, especially for lesions located at challenging or inoperable brain regions. However, a randomised, controlled, SRS versus anterior temporal lobe open surgery trial was conducted by Barbaro et al in patients with intractable unilateral mesial temporal lobe epilepsy. They found that anterior temporal lobe resection was better than SRS in terms of epilepsy remission, and that both SRS and anterior temporal lobe resection were as effective and safe as other treatments for temporal lobe epilepsy. SRS is an alternative to anterior temporal lobe surgery in patients who have contraindications or do not wish to undergo open surgery. ${ }^{15}$

There may be multiple causes of seizure recurrence after surgery in patients with temporal lobe epilepsy. According to Harroud et al, the most common causes of temporal lobe epilepsy surgery failure are: (1) inadequate medial temporal lobe excision, (2) recurrence in the lateral temporal lobe, (3) coexistence with mesial temporal lobe sclerosis and neocortical lesions (double pathology), and (4) extra-temporal lobe epilepsy mimicking temporal lobe epilepsy or plus temporal epilepsy. ${ }^{16}$ Based on the postoperative MRI findings, our patient's recurrent seizures after temporal lobe epilepsy surgery might have been due to insufficient resection of the region with focal cortical dysplasia. Additionally, the location of the residual lesion on MRI was consistent with the surface EEG findings.

Our patient was eligible for reoperation with conventional surgery or radiosurgery. After comparing SRS with 


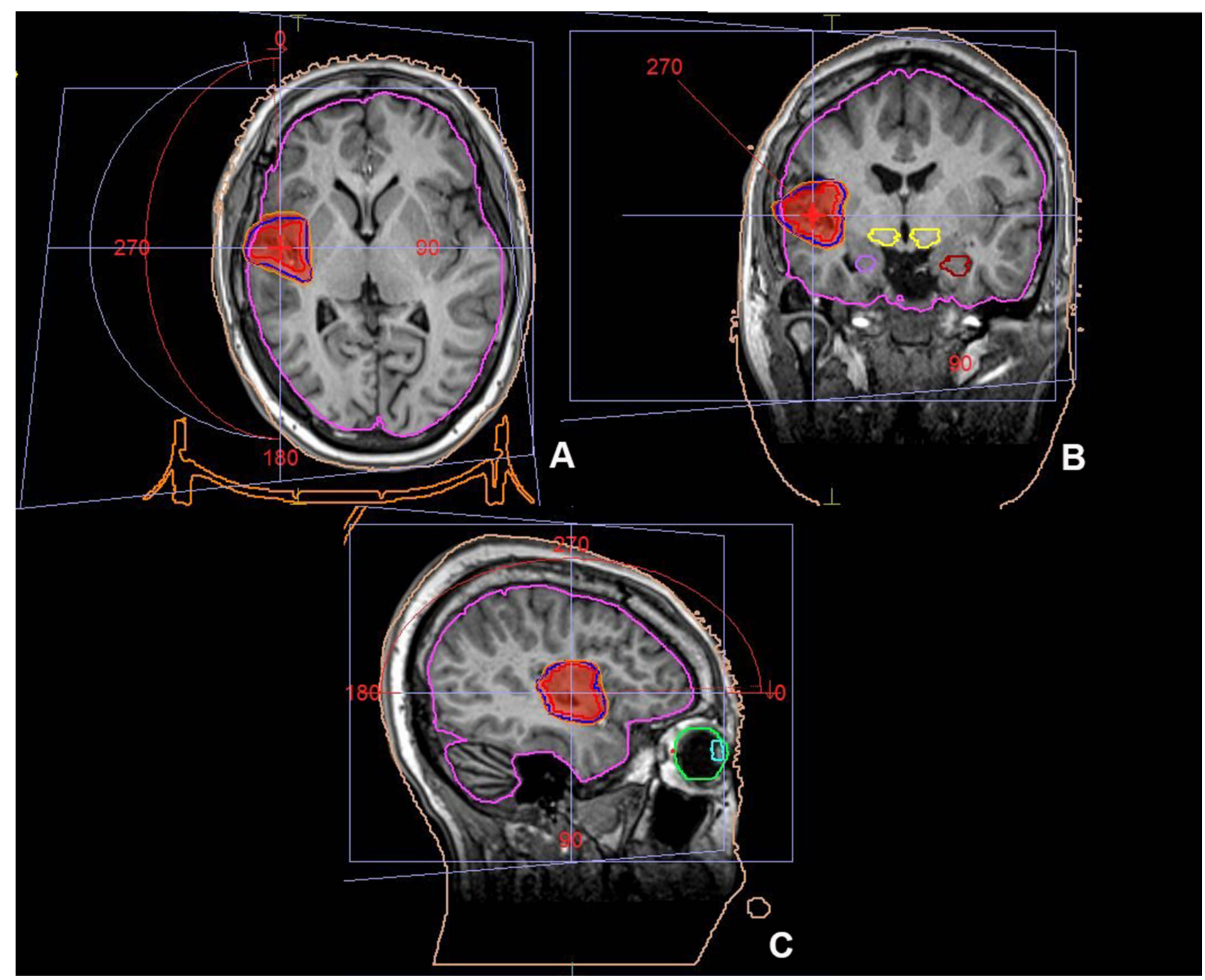

Figure 5 Stereotactic radiosurgery plan for the right operculo-insular area in the coronal (A), axial (B) and sagittal (C) views.

conventional surgery, we chose radiosurgery because of the high risk of damage to the adjacent cortices and hippocampus associated with open surgery. Our patient successfully underwent SRS without any clinical or radiological complications. She was maintained on two anti-epileptic medications following treatment (valproate and levetiracetam) and was seizure free at the time of this report (during four weeks after SRS). Monthly follow up was planned for seizure evaluation and to perform EEG and MRI. She will be gradually reduced the daily dose and/or the number of anti-epileptic medications.

Little is known about the effects of SRS on cognitive function in patients with temporal lobe epilepsy. Régis et al suggested that SRS may have a lesser impact on cognitive function than standard surgery. ${ }^{17}$ Srikijvilaikul et al reported no significant memory impairment at six months after radiosurgery but noticed a significant decrease in specific cognitive functions in three of the four patients studied. $^{11}$ McDonald et al reported a significant decrease in at least one measure of verbal memory, intelligence quotient, visual memory, and language in three patients who underwent dominant hemisphere radiosurgery. ${ }^{18}$ Notably, worse cognitive outcomes were observed in patients irradiated with higher doses. ${ }^{10}$

At time of this report, the patient has spent four weeks post-radiosurgery. The patient needs to longterm follow up to determine the seizure control of SRS. However, the patient lives in the north of Vietnam which is about 12 hours driving to our hospital and she has not returned due to the Covid-19 pandemic in Vietnam so far. Therefore, no MRI after SRS were obtained to provide adequate information. This is one of 


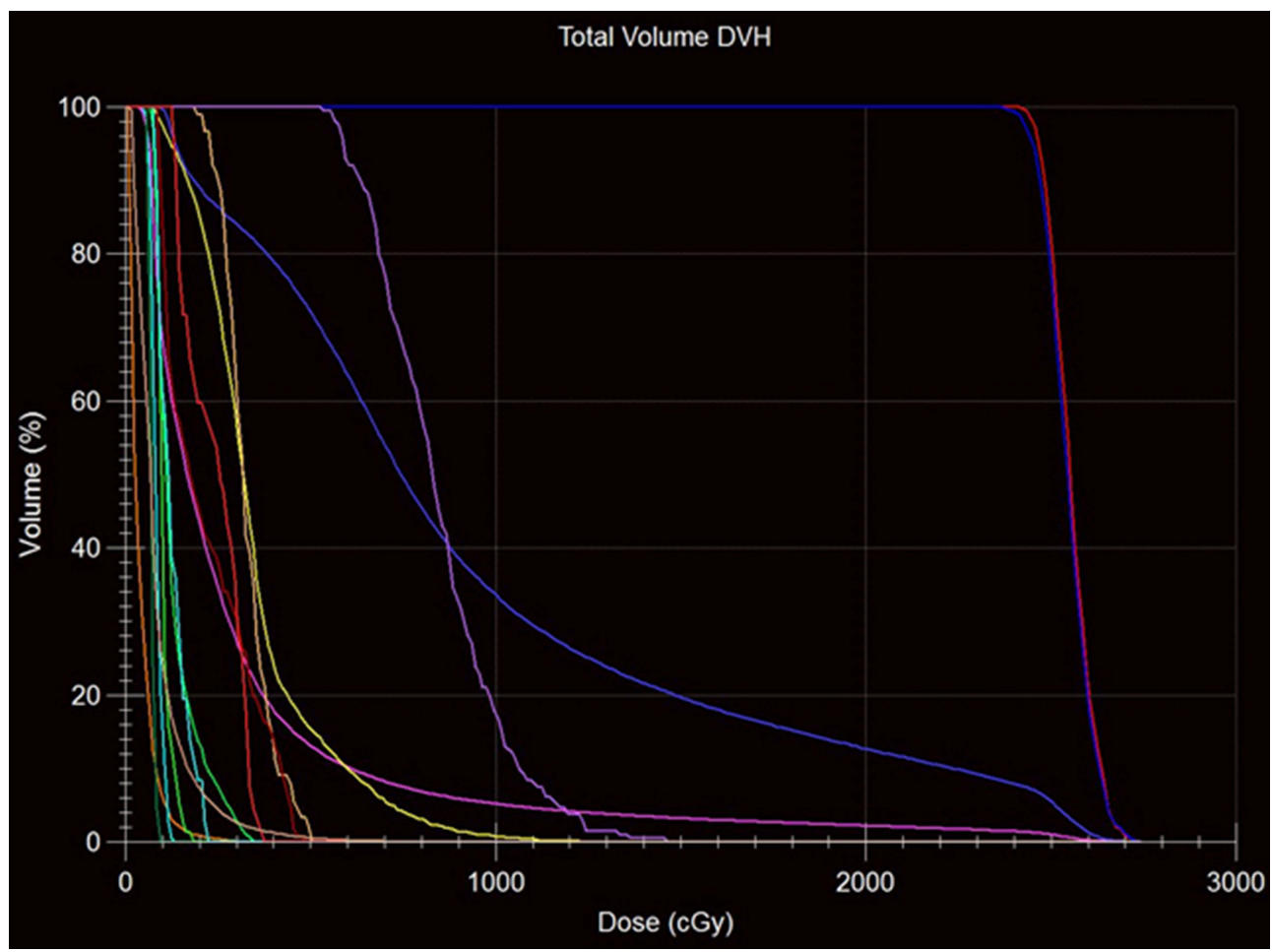

Figure 6 Dose-volume histogram of gross target volume and organs at risk.

the limitations of our study. Nevertheless, the preliminary results free demonstrated the safety and efficacy of SRS for the treatment of intractable focal epilepsy or recurrent epilepsy after epilepsy surgery failure in children.

\section{Conclusions}

This case report emphasises that SRS can be a safe option for the treatment of intractable focal epilepsy or recurrent epilepsy after epilepsy surgery failure in children. Further long-term prospective studies with larger sample sizes are needed to determine the optimal dose and fractional schedule of SRS for intractable temporal lobe epilepsy, and to demonstrate its effectiveness in terms of seizure control and neuropsychological improvement.

\section{Abbreviation}

SRS, stereotactic radiosurgery; EEG, electroencephalography; MRI, magnetic resonance imaging; ECoG, electrocorticography.

\section{Ethical Approval}

Ethical approval to report this case was obtained from Hue Central Hospital Ethical Committee (approval number: 072020/NCKH-BVH).

\section{Informed Consent}

Written informed consents were obtained from the patient's parents for their anonymized information to be published in this article.

\section{Funding}

No funding resources.

\section{Disclosure}

The authors declare that they have no competing interests.

\section{References}

1. McCoy B, Benbadis SR. Approach to refractory childhood seizures. Therapy. 2010;7(5):497-506. doi:10.2217/thy.10.51

2. Kwan P, Brodie MJ. Early identification of refractory epilepsy. $N$ Engl J Med. 2000;342(5):314-319. doi:10.1056/NEJM200002033420503

3. Jayalakshmi S, Vooturi S, Gupta S, Panigrahi M. Epilepsy surgery in children. Neurol India. 2017;65(3):485-492. doi:10.4103/neuroindia. NI_1033_16

4. Feng ES, Sui CB, Wang TX, Sun GL. Stereotactic radiosurgery for the treatment of mesial temporal lobe epilepsy. Acta Neurol Scand. 2016;134(6):442-451. doi:10.1111/ane.12562

5. Quigg M, Barbaro NM. Stereotactic radiosurgery for treatment of epilepsy. Arch Neurol. 2008;65(2):177-183.

6. Quigg M, Rolston J, Barbaro NM. Radiosurgery for epilepsy: clinical experience and potential antiepileptic mechanisms. Epilepsia. 2012;53 (1):7-15. doi:10.1111/j.1528-1167.2011.03339.x 
7. Englot DJ, Han SJ, Rolston JD, et al. Epilepsy surgery failure in children: a quantitative and qualitative analysis. J Neurosurg Pediatr. 2014;14(4):386-395. doi:10.3171/2014.7.PEDS13658

8. Ramantani G, Strobl K, Stathi A, et al. Reoperation for refractory epilepsy in childhood: a second chance for selected patients. Neurosurgery. 2013;73(4):695-704; discussion 704. doi:10.1227/ NEU.0000000000000081

9. Barbaro NM, Quigg M, Broshek DK, et al. A multicenter, prospective pilot study of gamma knife radiosurgery for mesial temporal lobe epilepsy: seizure response, adverse events, and verbal memory. Ann Neurol. 2009;65(2):167-175. doi:10.1002/ana.21558

10. Vojtech Z, Vladyka V, Kalina M, et al. The use of radiosurgery for the treatment of mesial temporal lobe epilepsy and long-term results. Epilepsia. 2009;50(9):2061-2071. doi:10.1111/j.1528-1167.2009. 02071.x

11. Srikijvilaikul T, Najm I, Foldvary-Schaefer N, Lineweaver T, Suh JH, Bingaman WE. Failure of gamma knife radiosurgery for mesial temporal lobe epilepsy: report of five cases. Neurosurgery. 2004;54 (6):1395-1402; discussion 1402-1394. doi:10.1227/01.NEU.000012 4604.29767.EB

12. Barcia JA, Barcia-Salorio JL, Lopez-Gomez L, Hernandez G. Stereotactic radiosurgery may be effective in the treatment of idiopathic epilepsy: report on the methods and results in a series of eleven cases. Stereotact Funct Neurosurg. 1994;63(1-4):271-279. doi:10.1159/000100331
13. Schrottner O, Eder HG, Unger F, Feichtinger K, Pendl G. Radiosurgery in lesional epilepsy: brain tumors. Stereotact Funct Neurosurg. 1998;70(Suppl 1):50-56. doi:10.1159/000056406

14. Whang CJ, Kwon Y. Long-term follow-up of stereotactic gamma knife radiosurgery in epilepsy. Stereotact Funct Neurosurg. 1996;66 (Suppl 1):349-356. doi:10.1159/000099735

15. Barbaro NM, Quigg M, Ward MM, et al. Radiosurgery versus open surgery for mesial temporal lobe epilepsy: the randomized, controlled ROSE trial. Epilepsia. 2018;59(6):1198-1207. doi:10.1111/epi.14045

16. Harroud A, Bouthillier A, Weil AG, Nguyen DK. Temporal lobe epilepsy surgery failures: a review. Epilepsy Res Treat. 2012;2012:201651. doi:10.1155/2012/201651

17. Regis J, Kerkerian-Legoff L, Rey M, et al. First biochemical evidence of differential functional effects following gamma knife surgery. Stereotact Funct Neurosurg. 1996;66(Suppl 1):29-38. doi:10.1159/000099698

18. McDonald CR, Norman MA, Tecoma E, Alksne J, Iragui V. Neuropsychological change following gamma knife surgery in patients with left temporal lobe epilepsy: a review of three cases. Epilepsy Behav. 2004;5(6):949-957. doi:10.1016/j.yebeh.2004. 08.014
International Medical Case Reports Journal

\section{Publish your work in this journal}

The International Medical Case Reports Journal is an international, peer-reviewed open-access journal publishing original case reports from all medical specialties. Previously unpublished medical posters are also accepted relating to any area of clinical or preclinical science. Submissions should not normally exceed 2,000 words or 4
Dovepress

published pages including figures, diagrams and references. The manuscript management system is completely online and includes a very quick and fair peer-review system, which is all easy to use. Visit http://www.dovepress.com/testimonials.php to read real quotes from published authors. 